\title{
Avoiding Bleeding in the Modified Bentall Procedure
}

\author{
Uberto Bortolotti, MD ${ }^{1}$ \\ ${ }^{1}$ Division of Cardiac Surgery, University Hospital, Pisa, Italy \\ Aorta (Stamford) 2021;9:92-93.
}

After more than 50 years from the original description, the modified Bentall procedure (MBP) still represents the goldstandard treatment for patients with aneurysms of the ascending aorta and with an aortic valve not amenable to repair. ${ }^{1}$ The MBP implies several suture lines, all of which are at risk for postoperative bleeding, especially in the presence of fragile tissues, as in patients with aortic dissection or Marfan syndrome. Techniques providing accurate hemostasis are, therefore, a prerequisite for a successful outcome and reduction of postoperative morbidity. This is particularly true when the proximal suture is performed, which fixes the composite conduit in place; in fact, once the aortic cross clamp is released, any bleeding site from the posterior aspect of such suture is almost impossible to reach.

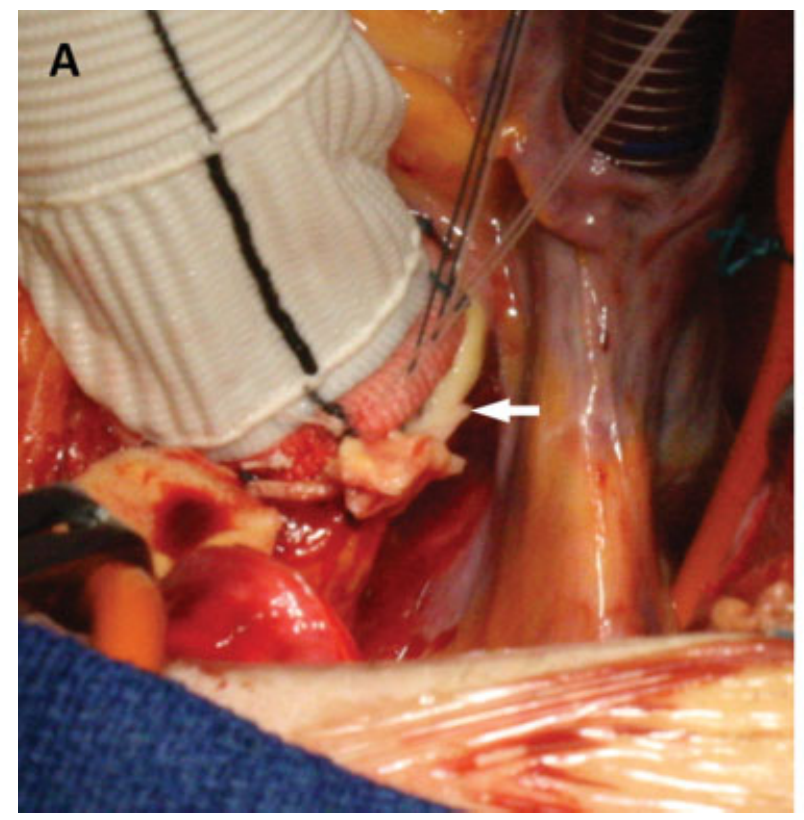

Address for correspondence Uberto Bortolotti, MD, Largo Traiano 23 Montegrotto Terme 35036, Italy (e-mail: uberto48@gmail.com).

In the February 2020 issue of AORTA, Kasai et al $^{2}$ described another technique to avoid postoperative bleeding from the proximal anastomosis after the MBP. In our experience, we have used, since the early 1990's, the technique proposed by Copeland et $\mathrm{al}^{3}$ in 1993, consisting of reinforcement of the proximal suture line with an additional suture. ${ }^{3}$ In our initial experience, when using this modification of the MBP, we observed a significant reduction in postoperative bleeding, the need for blood transfusions, and chest reexplorations. ${ }^{4}$ My colleagues and I have continued to routinely perform the MBP using this additional suture line with extreme satisfaction ( - Fig. 1); it takes less than 5 minutes to be performed, it does not influence the length of ischemic time, and it does not affect either morbidity or mortality.

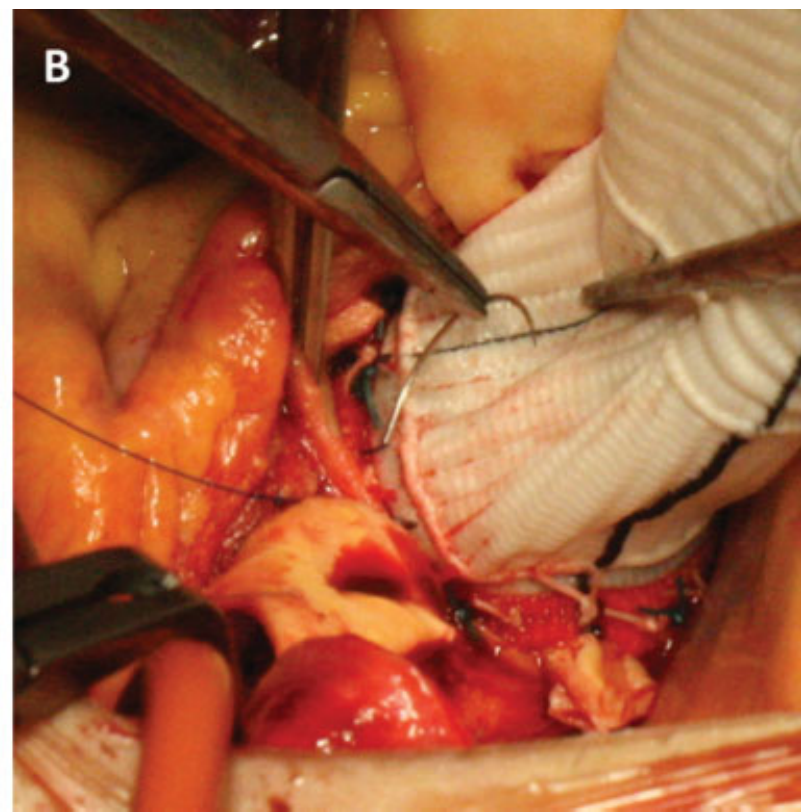

Fig. 1 (A) In the modified Bentall procedure, a rim of aortic wall is visible after the conduit is seated (arrow). (B) A stitch of 3/0 polypropylene is used to reinforce the proximal suture.

published online

October 7, 2021
DOI https://doi.org/

$10.1055 / \mathrm{s}-0041-1725120$

ISSN 2325-4637.

\section{(c) 2021. The Author(s).}

This is an open access article published by Thieme under the terms of the Creative Commons Attribution License, permitting unrestricted use, distribution, and reproduction so long as the original work is properly cited. (https://creativecommons.org/licenses/by/4.0/)

Thieme Medical Publishers, Inc., 333 Seventh Avenue, 18th Floor, New York, NY 10001, USA 
Kasai et $\mathrm{al}^{2}$ have used the technique they describe using a home-made mechanical conduit. This is quite surprising given the large variety of currently available mechanical conduits, most of which include the Valsalva graft. Therefore, I feel that the technique they propose may probably find more application when utilizing biological conduits for the MBP, which have to be constructed in the operating room. In my opinion, when performing the MBP with mechanical conduits, use of commercially available devices with a reinforcing not time-consuming proximal suture line, appears sounder.

Funding

None.

\section{Conflict of Interest}

The authors declare no conflict of interest related to this article.

\section{Acknowledgments}

None.

\section{References}

1 Lechiancole A, Celiento M, Isola M, et al. Modified Bentall procedure: mechanical vs biological valved conduits in patients older than 65 years. Int J Cardiol 2019;296:38-42

2 Kasai M, Yoshitake A, Shimizu H. Hemostatic modification of the Bentall procedure using an overlap suture technique. Aorta (Stamford) 2020;8(01):18-20

3 Copeland JG III, Rosado LJ, Snyder SL. New technique for improving hemostasis in aortic root replacement with composite graft. Ann Thorac Surg 1993;55(04):1027-1029

4 Pratali S, Milano A, Codecasa R, De Carlo M, Borzoni G, Bortolotti U. Improving hemostasis during replacement of the ascending aorta and aortic valve with a composite graft. Tex Heart Inst J 2000;27(03):246-249 